\title{
Application of thin layer chromatography for qualitative analysis of gunpowder in purpose of life prediction of ammunition
}

\begin{abstract}
Thin layer chromatography can be used to monitor the progress of a reaction, identify compounds present in a given mixture, and determine the purity of a substance. A number of enhancements can be made to the original method to automate the different steps, to increase the resolution achieved with TLC and to allow more accurate quantitative analysis. This method is referred to as "high-performance TLC". Our goal is to examine and to compare the quality of the results obtained by thin-layer chromatography, high-performance thin layer chromatography and vacuum stability test in the analysis of samples of gunpowders. Thin layer chromatography as a qualitative method has shown good quality of results that can be used for a good life prediction of the ammunition.
\end{abstract}

Keywords: thin-layer chromatography, high-performance thin layer chromatography, vacuum stability test, life prediction of the ammunition, gunpowder, diphenylamine, centralite I
Volume 5 Issue I - 2019

\author{
Halilović Namir, ${ }^{1,2}$ Raif Hadžić, ${ }^{2}$ Igor \\ Malešević, ${ }^{2}$ Miro Jurčević, ${ }^{2}$ Dražen Starčević ${ }^{2}$ \\ 'Department of Chemistry, University of Sarajevo, Bosnia and \\ Herzegovina \\ ${ }^{2}$ Ammunition Surveillance Laboratory,Armed Forces of B\&H, \\ Bosnia and Herzegovina
}

Correspondence: Halilović Namir, Faculty of Science, Department of Chemistry, University of Sarajevo, Sarajevo, Bosnia and Herzegovina, Tel 00-387-6I-495-3II, Email namir.halilovic@live.com

Received: December 26, 2018 | Published: January 09, 2019

\section{Introduction}

One of the major problems concerned with the manufacture and use of propellants is the measurement of their chemical stability and the prediction of their safe storage life. ${ }^{1}$ At normal storage temperature of $21-30^{\circ} \mathrm{C}$, propellants should have a safe shelf-life of 140 years, and a minimum of 35 years. ${ }^{2}$ It is a characteristic property of nitrocellulosebased propellants that the nitric ester constituents e.g. nitroglycerin, nitrocellulose, undergo a slow decomposition even at ambient temperatures. A solution of nitrocellulose in methanol (concentration $0.40-0.45 \%$ ) showed depolymerization after exposure to light to the wave-length $302 \mathrm{~m} / \mathrm{i}$, whereas no depolymerization was detectable after exposure to the wave-lengths 334 and $365 \mu \mathrm{m}$. Solutions of the same nitrocellulose sensitized by adding ca. $1 \% \beta$-naphthylamine showed depolymerization at all the wave-lengths. ${ }^{3}$ the degradation products formed, unless removed, can cause a reduction in chemical stability which can lead to cook-off/self-ignition due to the exothermic nature of the reactions involved. In addition they can lead to a loss of calorific value, changes in ballistic properties and cracking in large diameter charges. Small amounts of stabilizing compounds are included in propellant formulations, either singly or as mixtures, in order to react with the degradation products, thus reducing the probability of the adverse effects. The single-temperature ageing procedure has shown to be a cost-effective method to assure that a propellant is sufficiently stable to be stored for 10 years at ambient storage conditions $\left(25^{\circ} \mathrm{C}\right)$ - this at least for propellants consisting of well-known and generally used propellant components. For propellants of new formulations, in particular with stabilizers and other relevant components which were not used before in propellant formulations, more elaborate methods, such as the multi-temperature ageing procedure, have to be used. ${ }^{4}$ In Edition 1 of this AOP as well as in earlier STANAGs based on stabilizer depletion using single temperature ageing, different ageing temperatures, ageing periods and sentencing criteria were applied to different propellant types. ${ }^{5}$

\section{Stabilizers in gunpowders}

Until recently, the stabilizers considered a group of aromatic compounds with the ability to react quickly with nitric oxides that occur during the thermal decomposition of nitrocellulose, thereby preventing their autocatalytic effect on further decomposition more recently, this group of stabilizers is treated as "secondary stabilizers" because they reduce the effects of decomposition that is already occurring. The term "primary stabilizers" refers to a group of compounds that prevent or slow down the thermal decomposition of nitrocellulose. ${ }^{6}$ Typical stabilizers for propellants are diphenylamine DPA, N-nitrosodiphenylamine NODPA and the urea derivates ethylcentralite $\mathrm{CI}$ and methylcentralite CII. ${ }^{7}$ The list of the most common organic stabilizers is shown in Table 1.

Table I List of most common organic stabilizers used in production of ammunition

\begin{tabular}{lll}
\hline Name & Chemical name & Formula \\
\hline Akardite I & I, I-Diphenylurea & $\mathrm{C}_{13} \mathrm{H}_{12} \mathrm{~N}_{2} \mathrm{O}$ \\
Akardite II & 3-methyl-I,I-diphenylurea & $\mathrm{Cl}_{4} \mathrm{H}_{13} \mathrm{~N}_{3} \mathrm{O}_{2}$ \\
Akardite III & I-Ethyl-I,3-diphenylurea & $\mathrm{C}_{15} \mathrm{H}_{16} \mathrm{~N}_{2} \mathrm{O}$ \\
Centralite I & I,3-Diethyl-I,3-diphenylurea & $\mathrm{C}_{17} \mathrm{H}_{2} 0 \mathrm{~N}_{2} \mathrm{O}$ \\
Centralite II & I,3-Dimethyl-I,3-diphenylurea & $\mathrm{C}_{15} \mathrm{H}_{16} \mathrm{~N}_{2} \mathrm{O}$ \\
DPA & Diphenylamine & $\mathrm{C}_{12} \mathrm{H}_{11} \mathrm{~N}$ or $\mathrm{C}_{6} \mathrm{H}_{5} \mathrm{NHC}_{6} \mathrm{H}_{5}$
\end{tabular}

\section{Nitrocellulose and mechanisms of its degradation}

The gunpowders for classical ammunition, whether single-phase, double or triple, as well as a large number of rocket fuels as the basic component of the composition contain nitrocellulose. Nitrocellulose has a similar aspect to cotton, is white and has a fibrous texture. It is produced from cellulose. ${ }^{8}$ Nitrocellulose $\left(\mathrm{R}-\mathrm{ONO}_{2}\right)$ has good energy 
and technological properties that enable the production of various types of gunpowders of different ballistic properties, temperature and burning speed, etc. The appearance of the nitrocellulose molecule is shown in Figure 1. The undesirable characteristic of nitrocellulose is chemical degradation with the release of gaseous products. One of simplified mechanisms of nitrocellulose degradation is shown bellow.

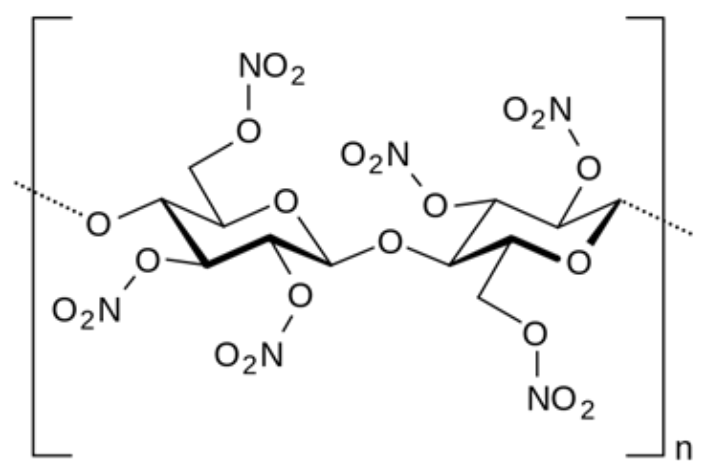

Figure I Nitrocellulose, $\mathrm{R}-\mathrm{ONO}$.

\section{Hydrolysis}

Long-term storage of nitrate ester compounds, they react with moisture inside or moisture around the packaging, resulting in nitric acid $\left(\mathrm{HNO}_{3}\right)$ and nitrogen oxides such as $\mathrm{NO}_{2}$ and $\mathrm{NO}_{3}$. These reactions of nitric oxide and nitric acid are exothermic reactions that increase the ambient temperature during decomposition: ${ }^{9}$

$$
\begin{aligned}
& \mathrm{RONO}_{2}+\mathrm{H}_{2} \mathrm{O} \rightarrow \mathrm{ROH}+\mathrm{H}^{+}+\mathrm{NO}^{-3} \\
& \mathrm{HNO}_{3} \Leftrightarrow \mathrm{H}^{+}+\mathrm{NO}^{-3} \\
& \mathrm{R}^{\prime} \mathrm{ONO}_{2}+\mathrm{H}+\rightarrow \mathrm{R}^{\prime} \mathrm{OH}+\mathrm{NO}^{+2} \\
& \mathrm{NO}^{+2}+\mathrm{NO}^{-3} \rightarrow \mathrm{N}_{2} \mathrm{O}_{5} \\
& \mathrm{~N}_{2} \mathrm{O}_{5}+\mathrm{H}_{2} \mathrm{O} \rightarrow 2 \mathrm{HNO}_{3} \Leftrightarrow 2 \mathrm{H}^{+}+2 \mathrm{NO}^{-3}
\end{aligned}
$$

\section{Definitions (AOP-48)}

Effective stabilizer is a defined term which is used to assess the stability in the single temperature test. Daughter stabilizers are substances with stabilizing capabilities that were not included in the propellant formulation but were produced from the initial stabilizers during propellant manufacture or ageing. Most stabilizer depletion products fall into this class. Certain stabilizers can appear both as initial stabilizer (incorporated in basic formulation) and as daughter stabilizer (produced from initial stabilizer), this even in the same propellant. Typical examples for such stabilizers are 2NDPA, 4NDPA, pNMA and pNEA - they can be used as initial stabilizers but are also formed from DPA, AKA-II, MC or EC. INITIAL STABILIZERS ("parent stabilizers") are stabilizers that were incorporated in the propellant formulation during manufacture. The content of "effective stabilizer" is calculated from the contents of all initial stabilizers (diphenylamine, 2-nitro-diphenylamine, ethyl centralite, methyl centralite, akardite-II, p-nitro-N-methylaniline, resorcinol-except if they are used as surface moderants) and the content of N-nitrosodiphenylamineas follows. For propellants without diphenylamine as well as for propellants with diphenylamine and other stabilizers.

\section{Effective stabilizer $=\Sigma$ (contents of initial stabilizers).}

For propellants with diphenylamine only:

A. Effective stabilizer $=$ content of diphenylamine +0.85 N-nitrosodiphenylamine.
Percentage effective stabilizer is the amount of effective stabilizer found, expressed as a percentage by weight of the propellant sample. Initial level is the percentage of effective stabilizer found in the propellant sample prior to ageing.

\section{Thin layer chromatography}

Thin layer chromatography (TLC) and high performance thin layer chromatography (HPTLC) - now also called planar chromatography - are, like all chromatographic techniques, based on a multistage distribution process. This process involves: a suitable adsorbent (the stationary phase), solvents or solvent mixtures (the mobile phase or eluent), and the sample molecules. For thin layer chromatography the adsorbent is coated as a thin layer onto a suitable support (e.g. glass plate, polyester or aluminium sheet). On this layer the substance mixture is separated by elution with a suitable solvent. The principle of TLC is known for more than 100 years now). ${ }^{10}$ TLC is a chromatography technique used to separate non-volatile mixtures. ${ }^{11}$ Thin-layer chromatography can be used to monitor the progress of a reaction, identify compounds present in a given mixture, and determine the purity of a substance. Specific examples of these applications include: analyzing ceramides and fatty acids, detection of pesticides or insecticides in food and water, analyzing the dye composition of fibers in forensics, assaying the radiochemical purity of radiopharmaceuticals, or identification of medicinal plants and their constituents. ${ }^{12}$ Thin-layer chromatography is performed on a sheet of glass, plastic, or aluminium foil, which is coated with a thin layer of adsorbent material, usually silica gel, aluminium oxide (alumina), or cellulose. This layer of adsorbent is known as the stationary phase.

After the sample has been applied on the plate, a solvent or solvent mixture (known as the mobile phase) is drawn up the plate via capillary action. Because different analytes ascend the TLC plate at different rates, separation is achieved. ${ }^{13}$ The mobile phase has different properties from the stationary phase. For example, with silica gel, a very polar substance, non-polar mobile phases such as heptane are used. The mobile phase may be a mixture, allowing chemists to finetune the bulk properties of the mobile phase. After the experiment, the spots are visualized. Often this can be done simply by projecting ultraviolet light onto the sheet; the sheets are treated with a phosphor, and dark spots appear on the sheet where compounds absorb the light impinging on a certain area. The plate is shown in (Figure 2-5) Chemical processes can also be used to visualize spots; anisaldehyde, for example, forms colored adducts with many compounds, and sulfuric acid will char most organic compounds, leaving a dark spot on the sheet. To quantify the results, the distance traveled by the substance being considered is divided by the total distance traveled by the mobile phase. (The mobile phase must not be allowed to reach the end of the stationary phase.) This ratio is called the retardation factor (Rf). If the solvent front is $6 \mathrm{~cm}$ then the $\mathrm{R}_{\mathrm{f}}$ value for the pigment at $3 \mathrm{~cm}$ would simply be 0.5 showed in Figure 2 .

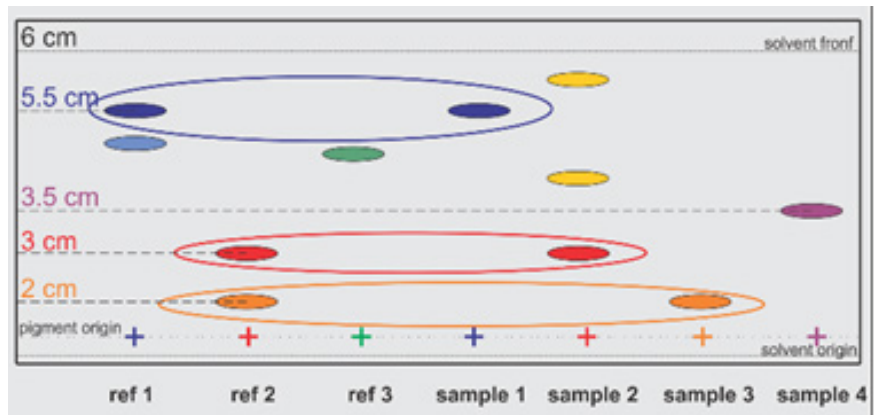

Figure 2 TLC plate with developed samples. 


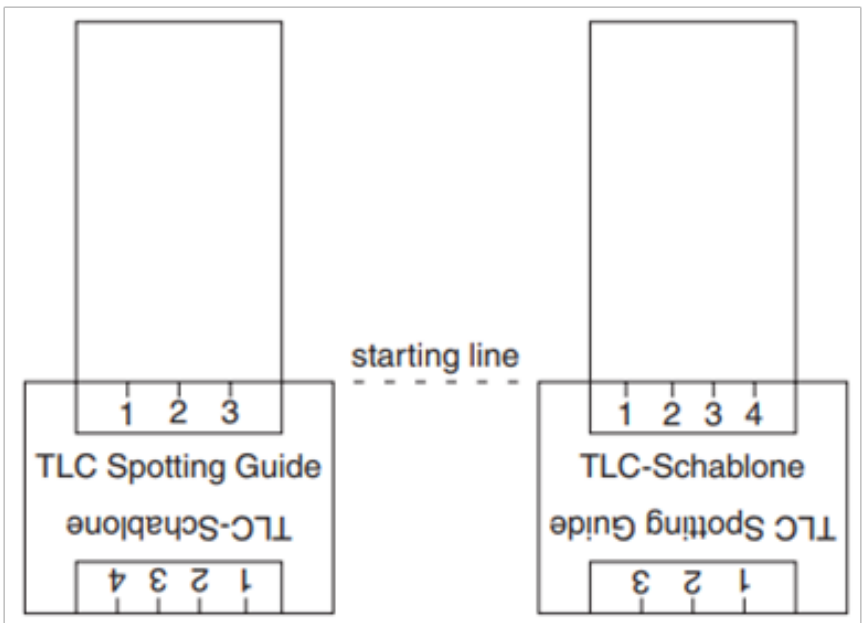

Figure 3 Application of a sample on a micro precoated sheet with the aid of a capillary and a TLC spotting guide. ${ }^{14}$

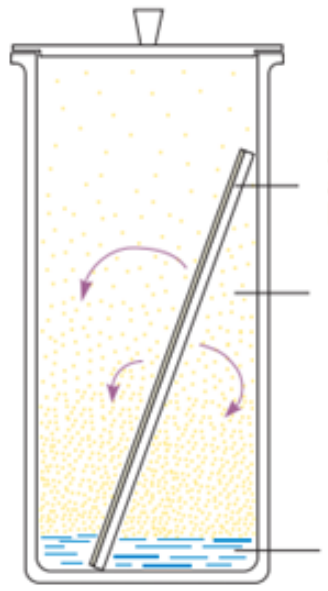

A

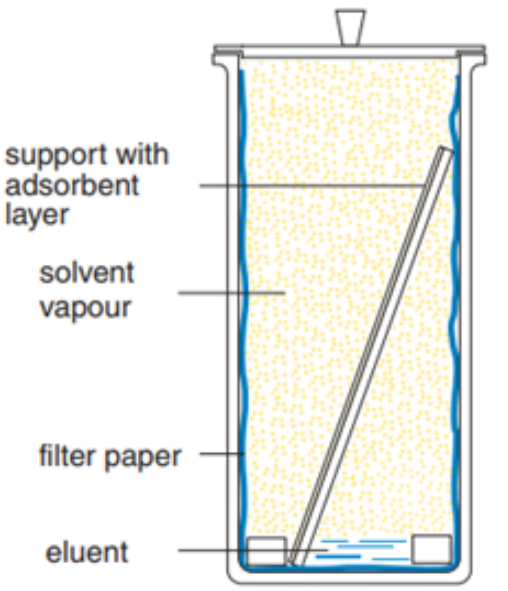

$\mathrm{B}$
Figure 4 Developing chambers and saturation. ${ }^{14}$

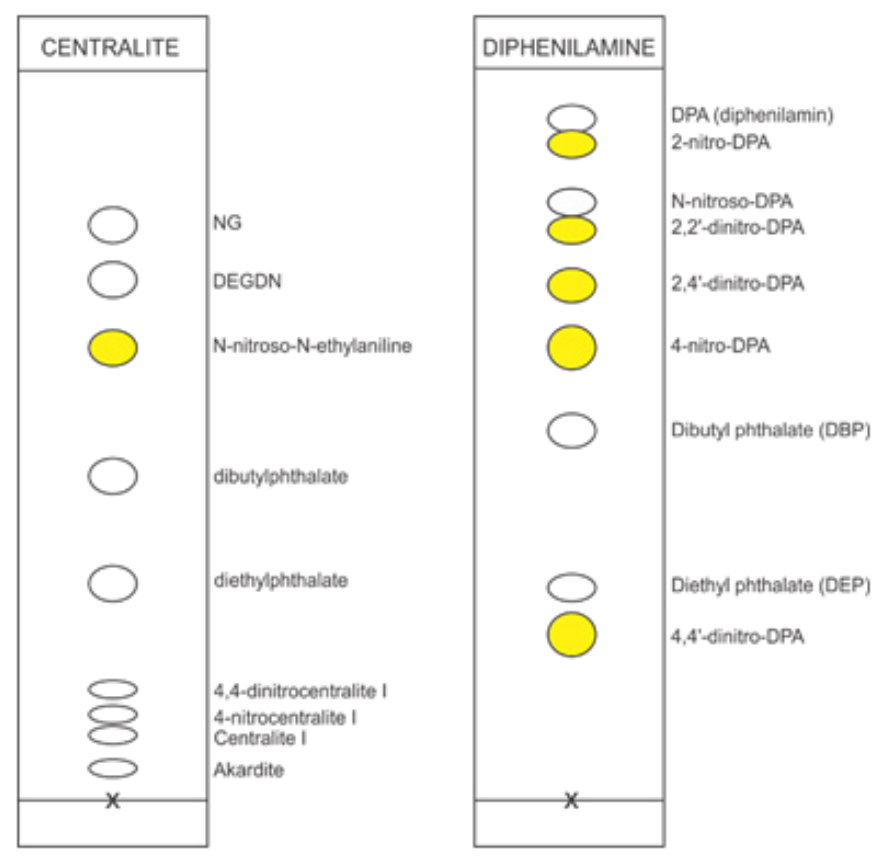

Figure 5 Chromatogram of standard mixtures,CENTRALIT (left) and DIPHENILAMIN (right) in the appropriate solutions.
$\mathrm{R}_{\mathrm{f}}=$ distance travelled by the component/distance travelled by the solvent. In the thin layer chromatography analysis, a glass plate is coated by adsorbent materials such as silica. Silica is the most commonly used adsorbent material for TLC analysis. Structurally silica gel consists of a matrix of Si-OH groups which can interact with molecules via hydrogen bonding and adsorption. A few micro liters of a dilute solution is put onto the silica surface of the plate using a micro capillary. This is known as "spotting". The plate is then placed in a jar containing a solvent (generally mixtures of ethylacetate and hexanes). As time goes, the solvent gradually rises up the plate due to capillary action carrying the components of the sample with it. Different molecules are carried up the plate to different distances due to variable interactions with the adsorbent material. For example, when silica is used, polar molecules with groups such as hydroxy $(\mathrm{OH})$ or amine $\left(\mathrm{NH}_{2}\right)$ will tend to form hydrogen bonds with the silica matrix $(\mathrm{Si}-\mathrm{OH})$ groups and will therefore not move as fast up the plate. While relatively non-polar molecules will have fewer interactions with the matrix and will tend to be more soluble in the solvent phase and therefore rise faster up with the solvent front. Once the solvent has risen a particular distance sufficient to separate components of the spot, the plate is either visualized directly using ultraviolet light, or it is developed using a stain to check for specific types of molecules.

In general, a substance whose structure resembles the stationary phase will have low $R_{f}$, while one that has a similar structure to the mobile phase will have high retardation factor. Retardation factors are characteristic, but will change depending on the exact condition of the mobile and stationary phase. For this reason, chemists usually apply a sample of a known compound to the sheet before running the experiment. The success of thin layer chromatography as a highly efficient micro analytical separation method is based on a large number of advantageous properties: high sample throughput in a short time suitable for screening tests pilot procedure for HPLC after separation the analytical information can be stored for a longer period of time (the TLC ready-to-use layer acts as storage medium for data) separated substances can be subjected to subsequent analytical procedures (e.g. IR, MS) at a later date rapid and cost-efficient optimisation of the separation due to easy change of mobile and stationary phase. ${ }^{14}$ For a better understanding of a thin layer chromatographic separation we describe here the basic steps:

a) Sample preparation.

b) Sample application development of a chromatogram, separation techniques evaluation in TLC - visualisation of separated substances.

c) Qualitative and quantitative determinations.

\section{Sample preparation}

For a chromatographic separation the sample must meet several requirements to obtain good results. It is not possible do go into detail here. However, eventually several steps for sample pretreatment may be necessary. These include sampling, mechanical crushing of a sample, extraction steps, filtration and sometimes enrichment of interesting components or clean-up, i.e. removal of undesired impurities. In our experiment, we prepared the samples of gunpowders into pieces of diameter up to $2 \mathrm{~mm}$ and extracted into dichloroethane.

\section{Sample application}

The aim of a chromatographic separation determines how the sample should be applied to the TLC plate or sheet. The most frequent technique still is application with a glass capillary as spot or short streak. Application as streak will yield better results especially for instrumental quantification. For both types of application some manual 
skill is required to obtain reproducible results. Substance zones which are too large from the beginning will cause poor separations since during chromatography they will become even larger and more diffuse.

Our TLC sets for example use this very simple way of application.

The mixture to be separated and the reference solution are applied to the micro pre coated sheets as spots by means of glass or plastic capillaries. Only use each capillary once to avoid contamination of the following samples. The capillaries fill themselves quickly when dipped into organic sample solutions, with aqueous solutions filling will be much slower. Before emptying the capillary roll the submerged end horizontally on filter paper. If the capillary is filled to the upper end, however, you may apply the "clean" upper end to the adsorbent layer. Place the capillary on the layer vertically and carefully, vertically so that the capillary empties itself and carefully to avoid damage to the layer. Damaged layers result in unevenly formed spots. To keep spots as small and compact as possible, it is advisable to apply a solution in several portions with intermediate drying (blow with cold or hot air). This is especially important for aqueous sample solutions. The following figures demonstrate the clean and easy application of samples with the above-mentioned spotting guide. It is recommended to apply $0.1-1 \%$ solution in the amount of $1-25 \mu$. The sample zone on the starting line should be $1-3 \mathrm{~mm}$ in diameter, $1-2 \mathrm{~cm}$ apart from the edge of the plate. For analytical work, the sample is applied in the amount of $1 \mu \mathrm{g}$ to $1 \mathrm{ng} .{ }^{14} \mathrm{~A}$ valuable aid for manual application especially of large volumes of very dilute samples is the concentrating zone (e.g. SIL G/UV254), which consists of a chromatographically inactive adsorbent. After application allow the solvent of the samples to evaporate completely (about 10minutes) or blow with cold or hot air. Development of a chromatogram should never start before the solvent of the applied samples is evaporated completely.

\section{Developing a chromatogram - separation techniques}

The most frequently used separation technique is ascending TLC in the customary trough chamber (standard method, linear development). Usually it is applied as single development. However, multiple development, with or without change of eluent (step technique) can improve separation results. For 2-dimensional development only 1 spot of the sample is applied in one edge of a plate. After chromatography in the first direction the plate is dried, turned by $90^{\circ}$ and developed in the 2 nd dimension with another eluent. Thus complicated mixtures give 2-dimensional chromatograms taking advantage of the different separating properties of two eluents. A generally applicable standardised optimisation method is described by $\mathrm{H}$ Keuker et al., ${ }^{15}$ It is important to pay attention to the atmosphere in the developing chamber. If reproducible migration distances are required, saturation of the chamber atmosphere with eluent vapour is necessary. For this purpose the developing chamber is lined with well absorbing chromatography paper (e.g. MN260) and charged with a correspondingly larger volume of eluent. Figure 4 shows:

A. Chamber with normal saturation. The arrows stand for the evaporation of the eluent from the layer and the dots symbolise the vapour density.

B. Chamber lined with filter paper, saturated with eluent vapour.

A better control of chromatographic conditions, especially of the vapour phase, is achieved in flat chambers (horizontal chambers) or a trough with sandwich configuration. In these techniques the vapour phase is excluded by a covering plate.

\section{Qualitative detection}

Qualitative evaluation is generally made directly on the TLC plate via the characteristic $R_{f}$ values of substances, i.e. the ratio of distance start - substance zone to distance start - solvent front and specific chemical reactions.

We made a qualitative determination in our experiments according to the Figure $5 \&$ Table 2-5 \& Table 6 .

Table 2 An example of coloring that can occur when determining the type of stabilizer

\begin{tabular}{llll}
\hline Diphenylamine & Centralite & DPA i CEN & Akardit \\
\hline blue & red & purple & brown \\
\hline
\end{tabular}

Table 3 Appearance of color as evidence of nitroglycerin

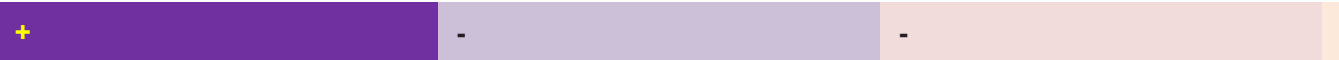

Table 4 Definitions of DPA stabilizer image

A Diphenylamine spot is much stronger than nitrodiphenylamine; barely recognizable 4-nitro-diphenylamine and 2-nitro-diphenylamine.

B Diphenylamine spot and nitrodiphenylamine are clearly dispersed, 4-nitr-diphenylamine and 2-nitro-diphenylamine clearly recognizable.

C Diphenylamine spot is less intense than nitrodiphenylamine, 4-nitro-diphenylamine and 2-nitro-diphenylamine clearly recognizable.

Diphenylamine spot has virtually disappeared; Nitrodiphenylamine clearly recognizable, 4-nitro-diphenylamine and 2 nitro-diphenylamine are clearly recognizable, no dinitroproducts are not recognizable.

E Nitrodifenylamine recognizable, dinitroproducts are recognizable.

F Nitrodifenylamines are not recognizable, dinitroproducts are recognizable.

Table 5 Estimation of diphenylamine stabilizer state

\begin{tabular}{|c|c|c|c|c|c|c|}
\hline & A & B & C & D & $\mathbf{E}$ & $\mathbf{F}$ \\
\hline \multicolumn{7}{|l|}{ Initial state } \\
\hline After aging & & & & & & \\
\hline
\end{tabular}


Table 6 Explanation of categories by Armed Forces B\&H, according to 4,5

\begin{tabular}{|c|c|c|c|c|}
\hline CATEGORY & Description & HPTLC & VST & $\begin{array}{l}\text { Safe storage } \\
\text { time at } 25^{\circ} \mathrm{C}\end{array}$ \\
\hline I & Gunpowder and rocket fuel good for storing & $\begin{array}{l}\text { At least } 50 \% \text { of initial stabilizer } \\
\text { concentration }\end{array}$ & $0-1 \mathrm{ml} / \mathrm{g}$ & 4 years \\
\hline 2 & $\begin{array}{l}\text { Gunpowder and rocket fuel good for storing, priority in the } \\
\text { use of ammunition labored with this gunpowder. }\end{array}$ & $\begin{array}{l}50 \% \text { of initial stabilizer concentration - } \\
0.2 \% \text { of stabilizer concentration }\end{array}$ & $\mathrm{I}-2 \mathrm{ml} / \mathrm{g}$ & 2 years \\
\hline
\end{tabular}

\section{Visualisation of separated substances}

First of all it is necessary to recognise the position of a substance spot. Only in very few cases the sample is a dye which can be seen with the naked eye. Much more often for unspecific visualisation substances can be viewed under UV light, since many substances show a UV absorption. If a fluorescent indicator is added to the layer, all substances absorbing in the respective region of wave length cause a quenching of the fluorescence, i.e. they appear as dark spots on the fluorescent layer. Customary fluorescent indicators are excited at $254 \mathrm{~nm}$ or (less frequently) at $366 \mathrm{~nm}$ with a mercury lamp showed in Table 7. The identification of separated substances is possible via the $\mathrm{R}_{\mathrm{f}}$ value compared to the pure compound, which is often applied simultaneously on the same plate. For a number of compounds their native fluorescence can be used for visualisation, which is excited by UV light (mostly long-wave UV) (e.g. aflatoxins). This allows not only determination of the $\mathrm{R}_{\mathrm{f}}$ value, but often enables a further qualitative assignment. Such compounds often occur in the extract of gunpowders. If these methods do not allow localisation or characterisation of substances, especially post-chromatographic detection methods can be applied chemical reactions on the TLC plate. Quite unspecific reactions are iodine adsorption and the charring technique (spraying with sulphuric acid and heat treatment). More reliable results are possible with specific reagents for spraying or dipping, which form colored or fluorescent compounds with the substances to be detected.

Table 7 Fluorescent indicators

\begin{tabular}{lll}
\hline Composition & $\begin{array}{l}\text { Absorption } \\
\text { maximum [nm] }\end{array}$ & $\begin{array}{l}\text { Colour of } \\
\text { fluorescence }\end{array}$ \\
\hline Manganese-activated zinc silicate & 254 & green \\
Inorganic fluorescent pigment & 366 & blue \\
\hline
\end{tabular}

\section{Qualitative assessment of TLC plates with gunpowder} samples

Because of the potential dangers of spontaneous combustion of $\mathrm{NC}$ propellants in Warehouse ordnance, which could be with disastrous consequences, a series of procedures was developed in order to control their chemical stability. ${ }^{16}$ The assessment process is based on comparing the developed sample with the standard.

\section{Experiment}

\section{Used equipment}
I. Block for sample heating.
II. Thermometer -10 to $1500 \mathrm{C}$.
III. TLC plates.

IV. Plan in the form of a plate of plastic.

V. UV lamp $254 \mathrm{~mm}$.

VI. Pipes with threaded plugs $100 \mathrm{ml}$ (3pcs).

VII. Set a blade.

VIII. Hubkolben pipettes $1000 \mu 1$.

IX. $1000 \mu \mathrm{l}$ spikes (100pcs).

X. Eppendorf cap 2ml (100pcs).

XI. Standard bottle with thread $4 \mathrm{ml}$ (100pieces).

XII. Plastic bottles with a dropper.

XIII. Safety glasses.

XIV. Laboratory gloves.

\section{Aging in metal block thermostats}

The kinetic behaviours at thermal accelerated ageing temperature is one of the most important aspects of propellants. ${ }^{17}$ The thermal decomposition of $\mathrm{NC}$ is a complex process which is believed to be catalyzed by the decomposition products, especially by reactive nitrogen oxides. ${ }^{18}$ The aging of the gunpowders in the laboratory involves the artificial warming of the sample of gunpowders in a thermocouple at a constant temperature. For aging, glass vials (different sizes) are used. Two samples of the same barrel are used in the experiment. To determine the safe storage stability at $25^{\circ} \mathrm{C}$, the following experimental temperatures are used:

Test temperature $80^{\circ} \mathrm{C}$ :

i. Four days for category 1 classification.

ii. Two days for category 2 classification.

The temperature selection is based on the Table $8 \&$ Table $9 .{ }^{19}$ In our experiment; we selected a test temperature of $80^{\circ} \mathrm{C}$, and a test period of 20 and 48 hours. This decision is based on the Table 8 .

\section{Determine the type of stabilizer}

When assessing the type of stabilizer, take into account the precise identification of the stabilizer, whether it is centralit (ethyl centralit, EC or $\mathrm{C} 1$ ) or diphenylamine (DFA or DPA). If they are together C1 and DPA, then the main stabilizer is DPA. The purple color indicates the presence of centralite and diphenylamine (DPA is considered or estimated as a more active stabilizer) showed in Table 9. The experiment is performed on a small quantity of gunpowder (or it extract in dichloroethane). Two drops of the appropriate reagent are added to the gunpowder sample, whereupon the color appears according to the table above. 
Table 8 Data of the required testing periods in order to determine the safe minimum storage stability at $25^{\circ} \mathrm{C}$ (a)

\begin{tabular}{|c|c|c|c|c|}
\hline $\begin{array}{l}\text { Storage time at } \\
25^{\circ} \mathrm{C} \text { [years] }\end{array}$ & $\begin{array}{l}\text { Equivalent test duration } \\
\text { at } 70^{\circ} \mathrm{C} \text { [hours] }\end{array}$ & $\begin{array}{l}\text { Equivalent test } \\
\text { duration at } 70^{\circ} \mathrm{C} \text { [days] }\end{array}$ & $\begin{array}{l}\text { Equivalent test duration } \\
\text { at } 80^{\circ} \mathrm{C} \text { [hours] }\end{array}$ & $\begin{array}{l}\text { Equivalent test } \\
\text { duration at } 80^{\circ} \mathrm{C} \text { [days] }\end{array}$ \\
\hline & 70 & 70 & 80 & 80 \\
\hline 0.5 & 31 & 1.3 & 10.4 & 0.43 \\
\hline I & 62.5 & 2.6 & 20.8 & 0.87 \\
\hline 2 & 125 & 5.2 & 41.7 & I.74 \\
\hline 4 & 250 & 10.4 & 83 & 3.5 \\
\hline 6 & 375 & 15.6 & 125 & 5.2 \\
\hline 8 & 500 & 20.8 & 167 & 6.9 \\
\hline 10 & 625 & 26 & 208 & 8.7 \\
\hline
\end{tabular}

Table 9 Data of the required testing periods in order to determine the safe minimum storage stability at $25^{\circ} \mathrm{C}$ (b)

\begin{tabular}{|c|c|c|}
\hline $\begin{array}{l}\text { Test } \\
\text { duration } \\
\text { [days] }\end{array}$ & $\begin{array}{l}\text { Equivalent storage life at } \\
25^{\circ} \mathrm{C} \text { for test temperature } \\
80^{\circ} \mathrm{C} \text { [years] }\end{array}$ & $\begin{array}{l}\text { Equivalent storage } \\
\text { life at } 25^{\circ} \mathrm{C} \text { for test } \\
\text { temperature } 70^{\circ} \mathrm{C} \\
\text { [years] }\end{array}$ \\
\hline I & I.I & 0.35 \\
\hline 2 & 2.3 & 0.75 \\
\hline 3 & 3.4 & I.I \\
\hline 4 & 4.6 & 1.5 \\
\hline 5 & 5.7 & 1.9 \\
\hline 6 & 6.9 & 2.3 \\
\hline 7 & 8 & 2.6 \\
\hline 8 & 9.2 & 3 \\
\hline 9 & 10.3 & 3.4 \\
\hline 10 & 11.5 & 3.8 \\
\hline 11 & 12.6 & 4.2 \\
\hline 12 & 13.8 & 4.6 \\
\hline
\end{tabular}

\section{Extraction of the stabilizer and determination of the} energy base

To determine the content of the stabilizer by the thin layer chromatography method, the sample is a gunpowder extract. In the experiment we extracted gunpowder samples in dichloroethane. The gunpowder can be mono-basic, double-basic or multi-basic. I A small amount of extract (the extract described in step two) succeeds in the trough (a few drops $\approx 50 \mu 1)$.

A. II Add one drop of acetic acid solution.

B. III Add about $1 \mathrm{mg}$ Zn.

C. IV Add three drops of reagent which contain sulfanilic acid and 1-naphthylamine.

If as a result we get is intense purple dyeing, then it's a doublebasic gunpowder. Nitroglycerin or some other nitrate ester, as the second energy base in the powder - mild violet color is not a proof of nitroglycerin. Double-base rocket propellants are nitrocellulose (NC)based energetic materials with a tendency towards slow, but constant thermal decomposition during aging. ${ }^{16}$ The visualization is shown in the Table 3 .

\section{Development of samples on TLC plate}

The development of samples on the TLC panel is shown in the Sample application paragraph. First, add the appropriate solution in a glass (chamber) to cover the bottom in a thickness of $2 \mathrm{~mm}$ of liquid. The solution we pour into a glass bottle is selected as follows:

1. Stabilizer diphenylamine: solution "DPA"

2. Stabilizer centralit: solution "CEN"

3. Stabilizer mixture: diphenylamine and centralite: solution "DFA"

4. Akardite stabilizer: analysis with bottle solutions ("CEN" and "DPA") is required, because the result of the accreditation is the production of nitro-DPA and diNitro-DPA, nitro-akardite and akardite, which are determined by the "CEN" solution.

\section{Evaluation of TLC plates}

After drying, in a darkened room, and under UV light, mark the visible points or points with their own color like in Figure 5.

\section{Estimation of gunpowder with stabilizer diphenylamine}

Estimation of gunpowders with stabilizer diphenylamine is based on the information shown in the Table 4. It is essential to compare the TLC plate of the sample with the standard in the (Figure 5) (Figure 6) according to. ${ }^{19}$

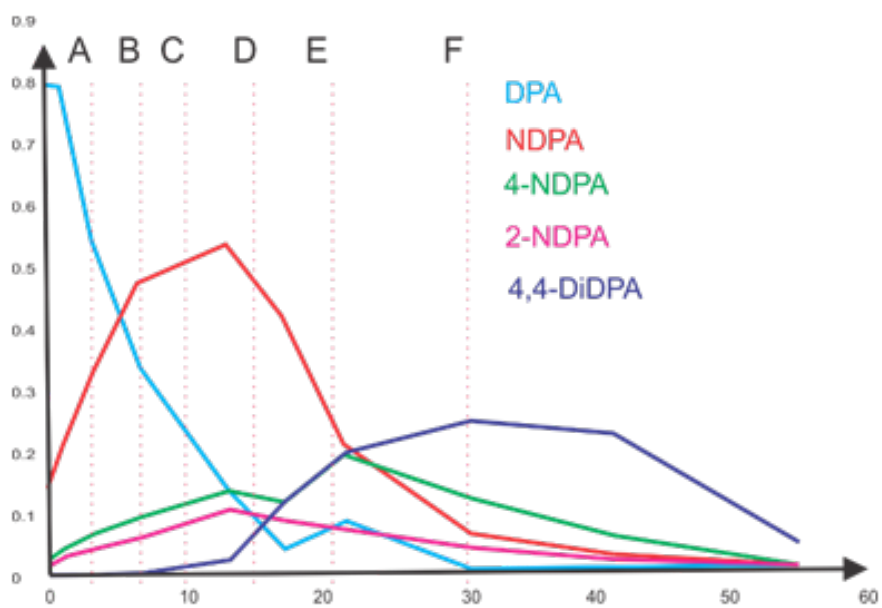

Figure 6 Degradation process of diphenylamine. 


\section{Awarding category 1:}

i. Image of the stabilizer in the initial state: A, B

ii. Image of the stabilizer after the equivalent of four years of aging at $25^{\circ} \mathrm{C}$ : not worse than $\mathrm{C}$.

\section{Awarding category}

i. Image of the stabilizer in the initial state: A, B, C, D

ii. Image of the stabilizer after aging equivalent of four years at $25^{\circ} \mathrm{C}$ : not worse than $\mathrm{E}$.

\section{Awarding category 3}

i. Image of the stabilizer in the initial state: E, F

ii. Image of the stabilizer after aging equivalent of four years at $25^{\circ} \mathrm{C}: \mathrm{F}$.

Decisions can be made according to the following table.

\section{Estimation of gunpowder with stabilizer centralite I}

i. Estimation of gunpowders with stabilizer centralite I is based on the information shown in the Table 10.

ii. It is essential to compare the TLC plate of the sample with the standard in the (Figure 5) (Figure 7).

Table 10 Definitions of a CEN I stabilizer image

A Centralit clear, barely recognizable $\mathrm{N}$-nitroso-ethylaniline and 4-nitro centralite.

B Centralit is clearly recognizable, nitroso-ethylaniline and 4-nitrocentralite are clearly recognizable.

Nitrozo ethylaniline and 4-nitro-centralite are clearly recognizable,

C dintro-centralite is eventually recognizable, centralit is still recognizable.

Dintro-centralite recognizable, nitrozo-ethylaniline and 4-nitrocentralite recognizable, the centrality virtually disappeared.

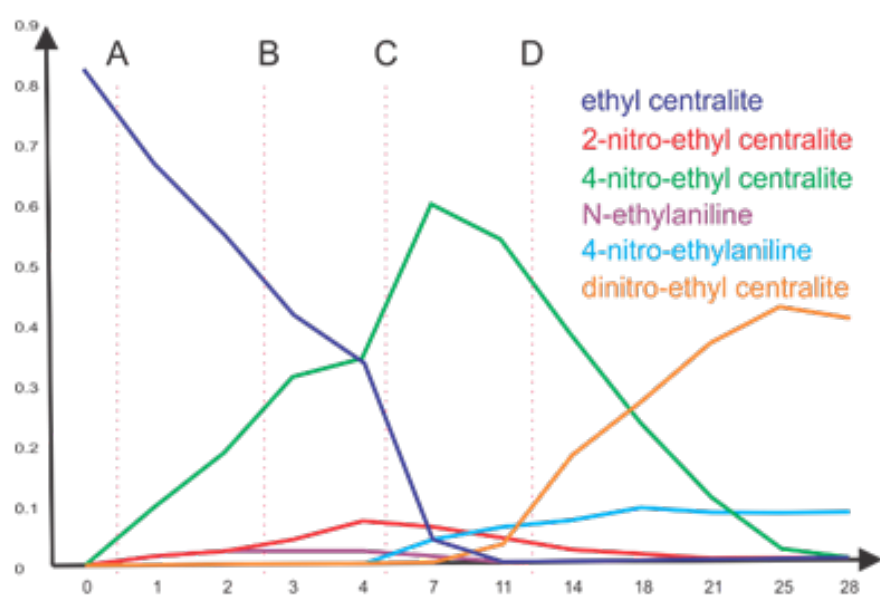

Figure 7 Degradation process of centralite I (ethyl centralite).

\section{Awarding category 1:}

i. Image of the stabilizer in the initial state: A.

ii. Image of the stabilizer after the equivalent of four years of aging at $25^{\circ} \mathrm{C}$ : not worse than $\mathrm{B}$.

\section{Awarding category 2:}

i. Image of the stabilizer in the initial state: A, B.

ii. Image of the stabilizer after aging equivalent of four years at $25^{\circ} \mathrm{C}$ : not worse than $\mathrm{C}$.

\section{Awarding category 3:}

i. Image of the stabilizer in the initial state: $\mathrm{C}$ or worse.

ii. Image of the stabilizer after aging equivalent of four years at $25^{\circ} \mathrm{C}$ : D or worse.

Decisions can be made according to the following table.

\section{Categorization of gunpowder according to standards AOP 48 and STANAG 4556}

Each country has its own categorization, and the indicative categorization is given in NATO standards. Smaller caliber ammunition contains 0.5 to $1 \%$ of initial DPA stabilizer; bigger caliber ammunition contains 1.5 to $2 \%$ of initial DPA stabilizer. ${ }^{20}$

\section{Results}

The results of the described experiment, in the titles above, are shown in the following Table 11. The same gunpowder samples were examined on TLC and two additional methods and we will make a comparison of the results. We analyzed 11 different samples of gunpowders of 6 types of cartridges $(20 \mathrm{~mm}, 40 \mathrm{~mm}, 76 \mathrm{~mm}$, $100 \mathrm{~mm}, 105 \mathrm{~mm}, 122 \mathrm{~mm})$. The results were processed and passed the appropriate categories and in the table above we can compare the categories obtained by the TLC method with the categories adopted on the basis of the other two methods: HPTLC and VST. All gunpowder samples are single-base (without nitroglycerin), which is confirmed by TLC method and VST method. The main stabilizer according to TLC is determined chemically where the result of the reaction is dyeing, as explained in the title Determine the type of stabilizer. DPA was determined in all gunpowder samples, which was confirmed by the HPTLC method. Eight samples showed a category matching, these are samples no. 1, 2, 3, 6, 8, 9, 10 and 11. Samples 4,5 , and 7 are identified by category 2 according to TLC method, and 1 st category by HPTLC and VST. The difference in grade may be due to the fact that TLC is qualitative, while HPTLC and VST are quantitative methods. The classical method depends on the eye of the observer, and this can be the cause of the different results. Sample number 4 showed a stabilizer ratio of $1.02 \%$, which is a category 1 characteristic, while the VST method showed $0.62 \mathrm{ml} / \mathrm{g}$ and it is a category 1 characteristic. We conclude that this is a transition group, as shown in (Table 5) (Table 12) by mixed green-yellow color. Sample number 5 is similar, however, the content of DPA is very high and the cause of disagreement in this case is probably human eye or inexperience. With this sample of gunpowder we can not say with certainty that it is the first category for HPTLC because we do not know how much the initial concentration of DPA was in the gunpowder. In case it was high, about $4 \%$, it would still be category 2. In this case, we were guided by a theoretical mean concentration of DPA quoted in gunpowders, about $1.5-2 \%{ }^{20}$ Sample number 7 is also in the transition group and it is not a mistake to say that it falls into category 2 of stability.

Samples 4, 5, and 7 belong to the transition group according to the TLC qualitative method, and because the method is qualitative, the attitude of our laboratory is to take a tougher decision, and this 
is one reason for disagreement with the mathematical decision of the other two methods. Obviously, this is a good matching result, and also, for this sample the initial concentration of the DPA stabilizer is not known. Samples 8, 9, 10 and 11 clearly showed the third category, which was confirmed by the other two methods. Clarity in determining the third category is the most important in this experiment. The problem that occurs in qualitative analysis on TLC is the appearance of colouration of spots at sites characteristic of DPA, N-nitroso-DPA, 2,2' and 2,4'-dinitro-DPA at the same time according to Figure 5. In this case, it is confusing which grade to select from (Table 4) (Table 10). Analyzing Figure 6, we can conclude that this is the sample in life range between $\mathrm{E}$ and $\mathrm{F}$. In practice, there is a high likelihood of errors in these cases. In such confusions, we advise group work, or to make a quantitative experiment on one of the appropriate methods.

Table I I Results of experiments on TLC, HPTLC and VST methods for II samples of gunpowder

\begin{tabular}{|c|c|c|c|c|c|c|c|c|c|c|c|c|c|c|c|c|c|c|c|c|}
\hline \multirow[t]{2}{*}{ No. } & \multirow[t]{2}{*}{$\begin{array}{l}\text { Name of } \\
\text { ammunition }\end{array}$} & \multirow[t]{2}{*}{ Gunpowder } & \multirow[t]{2}{*}{$\begin{array}{l}\text { Series of } \\
\text { gunpowder }\end{array}$} & \multicolumn{8}{|c|}{ High preasure thin layer chomatography } & \multicolumn{2}{|c|}{$\begin{array}{l}\text { Vacum } \\
\text { stability } \\
\text { test }\end{array}$} & \multicolumn{7}{|c|}{ Thin layer chomatorgraphy } \\
\hline & & & & 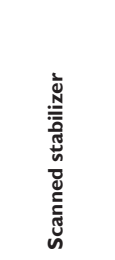 & 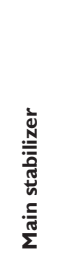 & 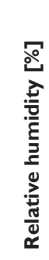 & 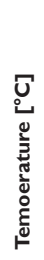 & 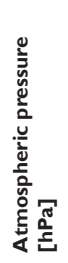 & 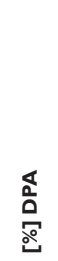 & 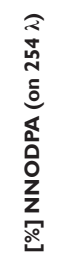 & 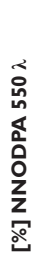 & $\begin{array}{l}\text { I } \\
\pm \\
\text { J } \\
z\end{array}$ & 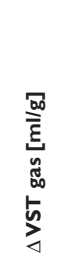 & $\frac{\mathscr{J}}{\tilde{D}}$ & 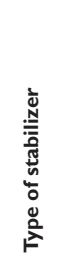 & 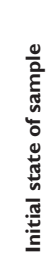 & 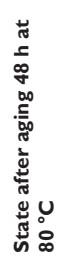 & 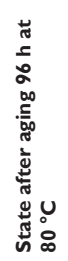 & 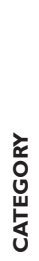 & 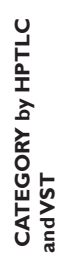 \\
\hline I & Bullet $100 \mathrm{~mm}$ & - & $14 / 7-39 / 67 \mathrm{~K}$ & $\begin{array}{l}\text { DFA, } \\
\text { NNODFA }\end{array}$ & DPA & 46 & 24 & 1019 & 1,63 & 0,50 & & - & 0,871 & 1 & DPA & $A$ & B & C & 1 & 1 \\
\hline 2 & Bullet $100 \mathrm{~mm}$ & NC 18 & MBL 7216 & $\begin{array}{l}\text { DFA, } \\
\text { NNODFA }\end{array}$ & DPA & 47 & 25 & 1025 & 1,11 & & & - & 1,639 & 1 & DPA & $A$ & C & $\mathrm{D}$ & 2 & 2 \\
\hline 3 & Bullet $122 \mathrm{~mm}$ & NC-43 & MBL 8318 & $\begin{array}{l}\text { DFA, } \\
\text { NNODFA }\end{array}$ & DPA & 46 & 24 & 1019 & 0,49 & & & - & 2,003 & 1 & DPA & B & E & E & 2 & 2 \\
\hline 4 & Bullet $40 \mathrm{~mm}$ & NCD-22 & MBL 8828 & DFA & DPA & 68 & 25 & 1013 & 1,02 & & - & - & 0,620 & I & DPA & C & C & D & 2 & I \\
\hline 5 & Bullet $76 \mathrm{~mm}$ & - & $9 / 7 \mathrm{I} / 68 \mathrm{~T}$ & $\begin{array}{l}\text { DFA, } \\
\text { NNODFA }\end{array}$ & DPA & 46 & 24 & 1019 & 1,73 & 0,34 & & - & 0,590 & 1 & DPA & A & B & $\mathrm{D}$ & 2 & I \\
\hline 6 & Bullet $20 \mathrm{~mm}$ & NCD-06 & MBL 6439 & $\begin{array}{l}\text { DFA, } \\
\text { NNODFA }\end{array}$ & DPA & 44 & 23 & 1023 & 0,70 & & & - & 1,537 & 1 & DPA & B & $\mathrm{D}$ & E & 2 & 2 \\
\hline 7 & Bullet $20 \mathrm{~mm}$ & NCD-07 & MBL 6746 & $\begin{array}{l}\text { DFA, } \\
\text { NNODFA }\end{array}$ & DPA & 44 & 23 & 1023 & 1,39 & & & - & 0,629 & 1 & DPA & B & C & E & 2 & 1 \\
\hline 8 & Bullet $122 \mathrm{~mm}$ & NC- 122 & MBL 8108 & $\begin{array}{l}\text { DFA, } \\
\text { NNODFA }\end{array}$ & DPA & - & - & - & $<0,2$ & & - & - & 2,513 & 1 & DPA & C & $\mathrm{E}$ & $\mathrm{F}$ & 3 & 3 \\
\hline 9 & Bullet $122 \mathrm{~mm}$ & NC-27 & MBL 8442 & $\begin{array}{l}\text { DFA, } \\
\text { NNODFA }\end{array}$ & DPA & - & - & - & $<0,2$ & & & - & 0,990 & 1 & DPA & C & $\mathrm{F}$ & $\mathrm{F}$ & 3 & 3 \\
\hline 10 & Bullet $122 \mathrm{~mm}$ & NC- 122 & MBL 790I & $\begin{array}{l}\text { DFA, } \\
\text { NNODFA }\end{array}$ & DPA & - & - & - & $<0,2$ & & & - & 2,246 & 1 & DPA & C & $\mathrm{E}$ & $\mathrm{F}$ & 3 & 3 \\
\hline 11 & Bullet $105 \mathrm{~mm}$ & $\mathrm{~B} 19 \mathrm{~T}(1.6)$ & 3I-BE-78 & $\begin{array}{l}\text { DFA, } \\
\text { NNODFA }\end{array}$ & DPA & 46 & 24 & 1019 & $<0,2$ & & & - & 3,437 & 1 & DPA & E & $\mathrm{F}$ & $\mathrm{F}$ & 3 & 3 \\
\hline
\end{tabular}

Table 12 Estimation of centralite I stabilizer state

\begin{tabular}{lllll}
\hline & A & B & C & D \\
\hline Initial state & & \|\|\|\|\|\|\|\|\|\|\|\|$\|$ & \\
After aging & & \|\|\|\|\|\|\|\|
\end{tabular}

\section{Conclusion}

The results of the experiments on three different methods, TLC, HPTLC and VST, have shown very good agreement. Determining the base of the gunpowders showed complete agreement by TLC and VST methods. Determining the type of stabilizers in the gunpowders showed complete agreement by TLC and HPTLC methods. Determining the category of the gunpowders by TLC showed very good agreement with HPTLC and VST methods. 8 of the 11 samples showed the identical category. The remaining 3 samples are in the transition category according to TLC method and Tables 8 and 10, which implies the situation in which the products of the decay of the stabilizer appear, and in the second hand the stabilizer has about $1 \%$ or more. The method of interpreting the results leads to apparent disagreement of the categories for the three samples under the numbers 4,5 and 7 in Table 11. For these three samples, this means that they are closer to the 2 nd than the 1 st category. Obviously, the results of the TLC method are very useful and usable for the purpose of life prediction of ammunition. Thin layer chromatography for the purpose of qualitative analysis of gunpowder samples is a reliable method and largely depends on the expertise of individuals and from the interpretations of the results. Results of qualitative thin layer chromatography analysis provides very good guidance in purpose of life prediction of gunpowders. Thin layer chromatography method can be economically employed for routine use because the consumption of mobile phase is low and, hence, there are scarcely any disposal problems. Thin layer chromatography method does not require the use of machines or special devices, it is fully portable and easy to handle and considerably cheaper than most commercial methods. 


\section{Acknowledgments}

None.

\section{Conflicts of interest}

Author declares that there is no conflicts of interest.

\section{References}

1. Garman NS, Picard JP, Polakoski S, et al. Prediction of safe life of propellants. Propellants Division. New Jersey: Dover; 1973:2.

2. Sang-Bong Lee, Jung-Wha Seo, Kyeong-Su Choi, et al. The Shelf-life Prediction of Single-Base Propellants by applying the Kinetic Model of n-th Order. Journal of the Korea Academia-Industrial cooperation Society. 2015;16(5):3633-3642.

3. Tadeusz Urbanski. Chemistry and Technology of Explosives. Pergamon Press Ltd; 1965: 275.

4. NATO. AOP-48, Explosives, Nitrocellulose based propellants, Stability test procedures and requirements using stabilizer depletion.

5. NATO. STANAG 4556, Explosives: Vacuum Stability Test.

6. Stojiljković S. Basics of diagnostics and monitoring of ammunition quality. Technical seminar. Safety in dealing with killings, storing, storing and destroying killer assets. Kragujevac; 2013.

7. Chovancová M, Očko P, Pechová A, et al. Lifetime prediction of propellants according to NATO standards. Slovak Republic: Military Technical and Testing Institute Zahorie; 2018:8.

8. Ángeles Fernández de la Ossa M, Torre M, García-Ruiz C. Nitrocellulose in propellants:Characteristics and thermal properties. Advances in Materials Science Research. 2012:7.

9. Ki-Hong Cho. A study on the self-life estimation of the propellant KM10 by using high temperature acceleration aging tests, Journal of the Korean Academy - Society for Industrial Cooperation. 2010;11(5):1735-1740.
10. Beyerinck MW. Z Phys Chem. 1889;3:110.

11. Harry W Lewis, Christopher J Moody. Experimental Organic Chemistry: Principles and Practice (Illustrated ed.). Wiley Blackwell; 1989:159-173.

12. Reich E, Schibli A. High-performance thin-layer chromatography for the analysis of medicinal plants. New York: 2007.

13. Vogel AI, Tatchell AR, Furnis BS, et al. Practical Organic Chemistry. 5th edn. 1989.

14. MACHEREY-NAGEL GmbH \& Co. KG. Basic principles of TLC. $2018 ; 269$.

15. Keuker H. Instrumental Thin Layer Chromatography. Brighton, Sussex, UK; 1989:105-114.

16. Jelisavac LJ. Life-time prediction of double-base propellants in accordance with Serbian and NATO standards. Scientific Technical Review. 2010;160(1):12-18.

17. Zhao Fengqi, Heng Shuyun, Hu Rongzu, et al. A study of kinetic behaviours of the effective centralite/stabilizer consumption reaction of propellants using a multi-temperature artificial accelerated ageing test. Journal of Hazardous Materials. 2007;145:45-50.

18. Arne Bergens, Rolf Danielsson. Decomposition of diphenylamine in nitrocellulose based propellants--i. Optimization of a numerical model to concentration-time data for diphenylamine and its primary degradation products determined by liquid chromatography with dual-amperometric detection. Talanta. 1995;42(2):171-183.

19. Armed Forces B\&H. Instructions for testing chemical stability of gunpowder. 2014.

20. Armed Forces B\&H. Chemical technology for ammunition testing. 2013. 